\title{
Development and performance of a livestock feed mixer
}

\begin{abstract}
In Nigeria, agricultural livestock production is lagging in efficiency thus resulting in low production output. Livestock feed need to be mixed very well, in other to achieve the best quality out of the livestock. There is gradual advancement from the past mixing method done manually to mechanization of livestock feed production process. In this study, a horizontal livestock feed mixer with a capacity of $100 \mathrm{~kg}$ was designed and a model of it was fabricated. The aim is to provide a base for commercial production of feed mixers in Nigeria using locally available materials with low cost of procurement. The machine was designed based on its power requirements, tension of belt, load on shaft pulley and belt tension, shaft diameter and weight of mixing drum. The materials are selected based on their flexibility, chemical compatibility, availability simplicity and low maintenance cost. The performance evaluation of the machine was carried out to determine the mixing efficiency using different feed capacity at different time intervals and percentage recovery rate on the feed rate. The mixing time and degree of mixing was observed to increase with increase in feed weight. The horizontal feed mixer developed is highly efficient, cost effective and solves problems associated with manual mixing during livestock feed production.
\end{abstract}

Keywords: sefficiency, feed mixer, livestock, mechanization, output
Volume 2 Issue 4 - 2018

\section{Daniyan IA, Aderoba AA, Atamunotoru DA,} Rominiyi OL

Department of Mechanical and Mechatronics Engineering, Afe Babalola University Ado Ekiti,

Nigeria

Correspondence: Daniyan IA, Department of Mechanical and Mechatronics Engineering,Afe Babalola University Ado Ekiti, Nigeria, Email afolabiilesanmi@yahoo.com

Received: March 30, 2018 | Published: July 30, 2018

\section{Introduction}

Feed production requires careful management and the process of production. Feed generation for animals, poultry or oceanic life includes a scope of exercise, which incorporates granulating, blending, pelleting and drying operations. ${ }^{1}$ There is high feasibility of the utilization of various forms of farm and agro-industrial wastes and by-products in the formulation of complete feeds for livestock, poultry and aquatic life. ${ }^{1-3}$ If feed is not properly mixed, ingredients and nutrients will not be properly distributed which mean that it will not meet the expected targeted nutritional composition. ${ }^{4,5}$ Feed production requires careful management in the process of production. Feed generation for animals, poultry or oceanic life includes a scope of exercise, which incorporates granulating, blending, pelleting and drying operations. ${ }^{1,6}$

According to Chikwado, ${ }^{7}$ the processing and densification of finely ground and mixed ingredients of animal feed into high density and durable pellets are pertinent to enhance homogeneity of feed and thereby improve animal growth, free flowing agglomerates (pellet), handling, storage and transportation.

According to Chikwado ${ }^{7}$ and $\mathrm{New}^{8}$ the mixing device is to achieve a uniform distribution of the components by means of flow, which is generated by mechanical means. After mixing, the feed is extruded and pelletized. In Nigeria, farmers face a plethora of problems in raising the livestock, aquatic life and poultry due to lack of access to quality feed at the right time and the cost implication. They are unable to procure the required machines to increase their production rate. The rate of poultry production does not meet the total human population growth and demand in the country due to the high cost of acquiring feeds at the market value. ${ }^{1,9}$ The feed mixing can be done manually and mechanically. The manual method of mixing feed entails using a shovel mix and characterized by low output, less efficient, labour intensive and can be hazardous to the health of the animal. The mechanical method of mixing is achieved by using mechanical mixers such as tumbler mixer, horizontal trough mixer, vertical screw mixer, etc. ${ }^{1}$ The aim of this work is to develop a horizontal feed mixer that is highly efficient, cost effective which solves problems associated with manual mixing during livestock feed production. This will provide a base for commercial production of feed mixers in Nigeria using locally available materials with low cost of procurement.

\section{Methodology}

The design calculations which was used for design and fabrication of the horizontal livestock feed mixer was hereby presented.

\section{Volume of mixing chamber}

The mixing chamber shown in Figure 1 is a cylinder. The volume $\mathrm{V}$ of the cylinder is given by:

$$
V=\pi \frac{d^{2}}{4} h
$$

Where

$\mathrm{d}$ is the diameter of the circular base $(0.60 \mathrm{~m})$ and $\mathrm{h}$ is the height of the cylinder $(1.10 \mathrm{~m})$. From equation 1 , the volume is given as;

$$
\begin{aligned}
& V=3.142 \times \frac{0.60^{2}}{4} \times 1.10 \\
& V=0.311 \mathrm{~m}^{3}
\end{aligned}
$$

\section{Torque of shaft}

According to Khurmi and Gupta, ${ }^{10}$ shafts may be designed on the basis of rigidity and strength. When subjected to twisting moment only, the torque developed in the shaft is given by equation 2 . 


$$
T=\frac{\pi \tau d^{3}}{16}
$$

Where;

$\mathrm{T}$ is the torque, $\tau$ is the maximum shear stress $\left(\mathrm{N} / \mathrm{m}^{2}\right)$ and $\mathrm{d}$ is the diameter of the shaft $(\mathrm{m})$.

$$
\tau=\frac{F}{A}
$$

F is the force acting on the body (N) and A is the cross-sectional area of the body $\left(\mathrm{m}^{2}\right)$

$$
\begin{aligned}
& A=\frac{\pi d^{3}}{4} \\
& F=m g
\end{aligned}
$$

Where;

$\mathrm{m}$ is the mass of the body $(\mathrm{kg})$ and $\mathrm{g}$ is the acceleration due to gravity $\left(\mathrm{m} / \mathrm{s}^{2}\right)$

$$
m=\text { density } \times \text { volume }
$$

The density is $1042 \mathrm{~kg} / \mathrm{m}^{3},{ }^{11}$ hence the volume of the cylinder is calculated as $0.311 \mathrm{~m}^{3}$.

Therefore,

$$
\begin{aligned}
& m=\frac{1042 \mathrm{~kg}}{m^{3}} \times 0.311 \mathrm{~m}^{3}=324.06 \mathrm{~kg} \\
& F=324.06 \times 9.81 \\
& F=3179 \mathrm{~N} \\
& \tau=\frac{4 F}{\pi d^{2}} \\
& \tau=\frac{4 \times 3179}{3.142 \times 0.6^{2}}=11241.95 \mathrm{~N} / \mathrm{m}^{2}
\end{aligned}
$$

From equation 2 , the shaft torque is calculated as

$$
T=\frac{3.14211241 .95 \times 0.6^{3}}{16}
$$

The torque of the shaft is $794.75 \mathrm{Nm}$

\section{Power transmission}

Power transmitted by the shaft is given by:

$$
p=T \frac{(2 \pi N)}{60}
$$

Where;

$\mathrm{P}$ is the power rating of the electric motor (Watt), $\mathrm{T}$ is the torque transmitted in $\mathrm{Nm}$ and $\mathrm{N}$ is the number of revolutions per minute (Assume the number of revolution per minute is 100)

$$
p \frac{=794.75 \times 2 \times 3.142 \times 100}{60}
$$

$$
\begin{aligned}
& \mathrm{P}=8323.68 \mathrm{~W} \\
& \mathrm{P}=8.32368 \mathrm{~kW}
\end{aligned}
$$

Using a power factor of 1.2 , the required power is calculated as $9.988 \mathrm{~kW}$. Hence, a $10 \mathrm{~kW}$ electric motor will produce sufficient motion for the belts and shafts.

\section{Belt speed}

According to Shigley, ${ }^{12}$ the belt speed of the driving pulley from the motor is expressed as

$$
V_{1}=\frac{\pi D_{1} N_{1}}{60,000}
$$

Where

$V$ is the belt speed (m/s), D1 is diameter of motor pulley $(\mathrm{mm})$, $\mathrm{N} 1$ is the speed of motor (rpm),

and $\pi$ is a constant.

$$
V_{1}=\frac{3.142 \times 90 \times 1435}{60000}
$$

$$
V_{1}=6.76 \mathrm{~m} / \mathrm{s}
$$

According to Shigley, ${ }^{12}$ the belt speed of the driven pulley from the driven pulley of $80 \mathrm{~mm}$ to the mixing pulley of $150 \mathrm{~mm}$ is expressed as:

$$
\begin{aligned}
& V_{2}=\frac{\pi D_{2} N_{2}}{60000} \\
& V_{2}=\frac{3.142 \times 80 \times 861}{60000}=3.61 \mathrm{~m} / \mathrm{s}
\end{aligned}
$$

\section{The drive}

V-belt and pulley arrangements were adopted to transmit power from the electric motor to the shaft of the mixing unit because of its flexibility, simplicity and low maintenance cost. It also has the ability to absorb shocks and mitigating the effects of vibratory forces. ${ }^{13}$

\section{Materials selection}

Since the components would be subjected to varying degree of stress, strain, force friction etc. hence suitable materials should be selected. Materials are selected for the purpose of serviceability, machinability and over all properties inclusive of design consideration. The properties of the materials used are favourable, cheap and readily available.

The machine components used in the fabrication are: stand, electric motor, belt, pulley etc. The mixing chamber is shown in Figure 1 while the hopper and shaft are shown in Figure 2, Figure 3 respectively. The developed livestock feed mixer is shown in Figure 4. 


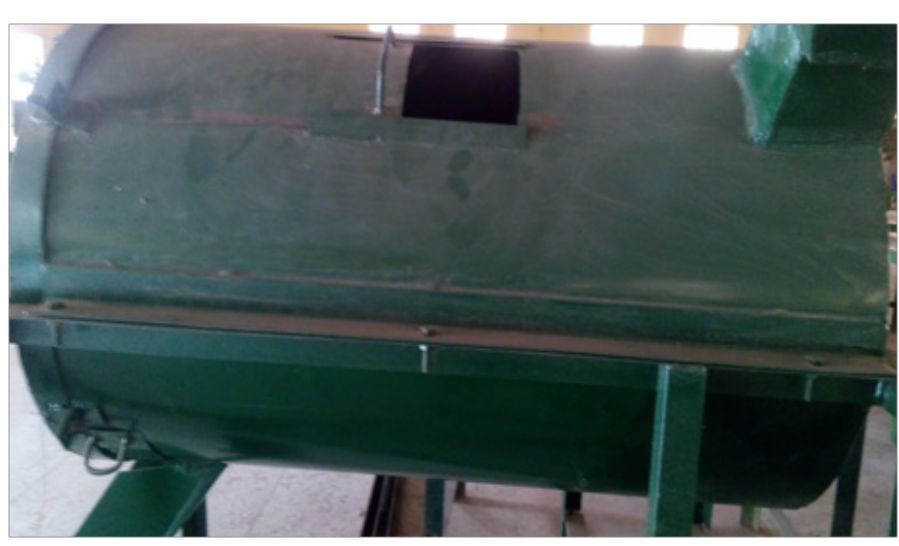

Figure I Mixing drum.

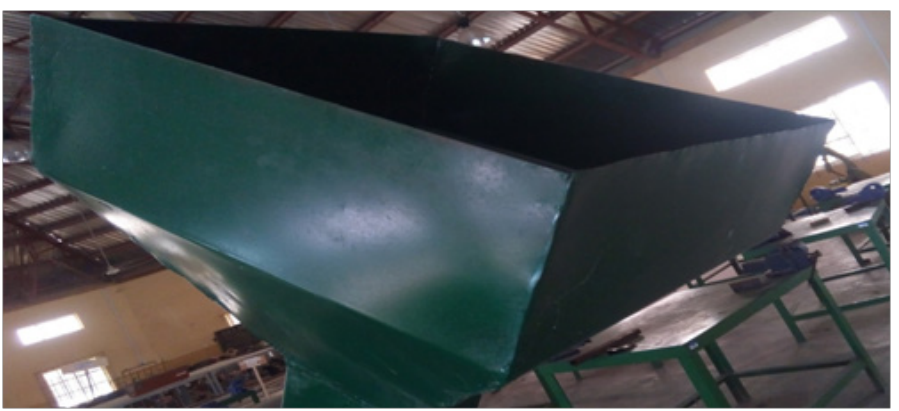

Figure 2 The hopper.

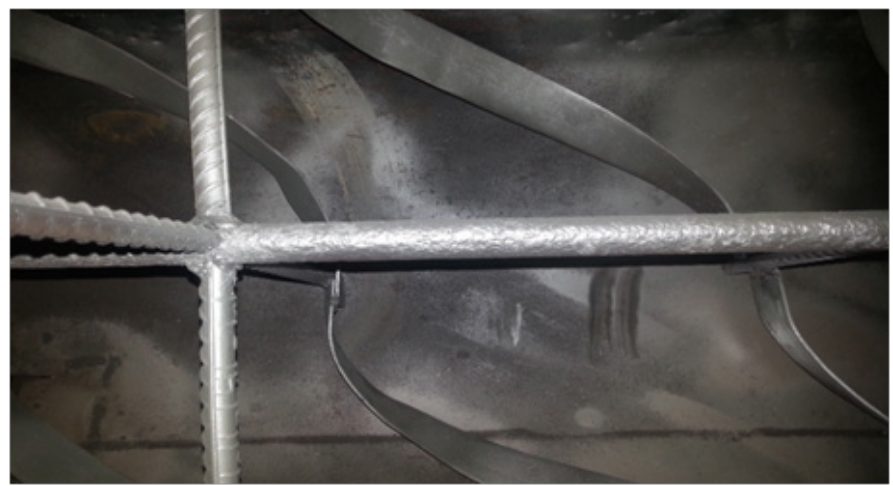

Figure 3 The shaft and ribbons

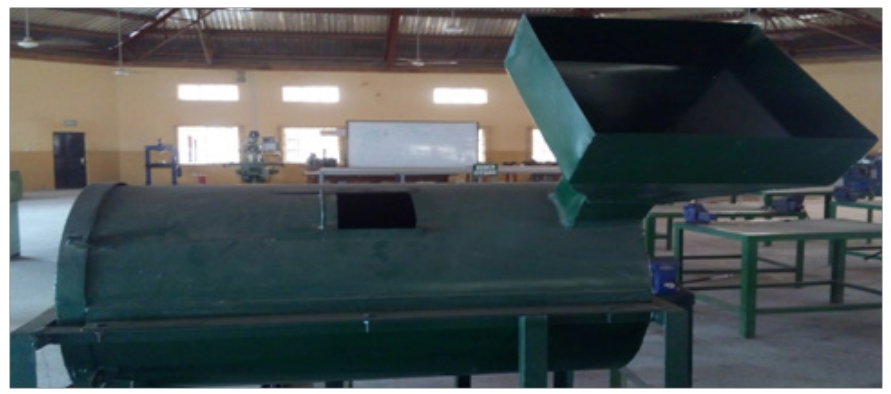

Figure 4 The developed livestock feed mixer.

\section{Machine tool and equipment used for fabrication}

These include: guillotine machine, standing drilling machine, cutting machine, electric arc welding machine, electric grinding machine, hammer, try square, table vice and lathe machine.

\section{Description of the developed feed mixer}

The machine consists of a main frame, mixing chamber (Figure 1), hopper (Figure 2) driving shaft, mixing ribbons (Figure 3). The main frame is made from 2 " $\times 2$ " mild steel angle bar. The angle bar is measured and cut into different lengths. The top part of the main frame is made by welding $1100 \mathrm{~mm} \times 700 \mathrm{~mm}$ length together. The legs of the frame which are $1150 \mathrm{~mm}$ are welded to the $1100 \mathrm{~mm} \times 700 \mathrm{~mm}$ top part of the main frame. The legs are then bent at an angle of $27^{\circ}$. The welding of the bottom part of the frame made of $1250 \mathrm{~mm} \times 800 \mathrm{~mm}$ angle bar. This makes up the frame of the machine The mixing chamber made of mild steel of $1.5 \mathrm{~mm}$ thickness is in cylindrical form is cut with guillotine machine into $1200 \mathrm{~mm}$ length and $1100 \mathrm{~mm}$ height. Two circles of diameter $600 \mathrm{~mm}$ are cut drilled at their centres. One of the circles is welded to the end of the mixing chamber while the other is lined with a flat bar and extensions fitted for the bolts and nuts.

Mixing ribbons are made by cutting and welding $16 \mathrm{~mm}$ mild steel rods to the shaft. The power unit which consist of V-belt transmit power from the variable electric motor rated $10 \mathrm{~kW}$ rotates at a maximum speed of $1450 \mathrm{rpm}$ and has the maximum frequency of $3000 \mathrm{~Hz}$. The driver pulley is $80 \mathrm{~mm}$ in diameter, drives two pulleys of $200 \mathrm{~mm}$ and $80 \mathrm{~mm}$ keyed together with V-belt.

\section{Results and discussion}

The following materials used for formulating fish feed mixture were used for testing the machine:

Groundnut cake, Soya bean meal, Maize, Rice Bran, Methionine, Lysine, Fish premix, DCP (Dibasic Calcium Phosphate dehydrate) and Vitamin C. The performance evaluation of the machine carried out to determine the mixing efficiency through using different feed capacity at different time intervals and percentage recovery rate on the feed rate. The first step was a mixture of $20 \mathrm{~kg}$ of fish feed and the result is presented in Table 1 and the relationship between the weight $(\mathrm{kg})$ and the percentage of materials mixed are plotted as in Figure 5.

Table I Weight and percentage of materials mixed to achieve $20 \mathrm{~kg}$ of fish feed

\begin{tabular}{llll}
\hline S/N & Materials & $\begin{array}{l}\text { Weight of } \\
\text { materials } \mathbf{( k g )}\end{array}$ & $\begin{array}{l}\text { Percentage } \\
\text { weight of } \\
\text { mixture }\end{array}$ \\
\hline I & Groundnut Cake & 4 & 20 \\
2 & Soya bean meal & 4 & 20 \\
3 & Maize & 4 & 20 \\
4 & Rice Bran & 4 & 20 \\
5 & Methionine & 1.5 & 7.5 \\
6 & Lysine & 0.5 & 2.5 \\
7 & Fish premix & 0.5 & 2.5 \\
8 & DCP & 0.5 & 2.5 \\
9 & Vitamin C & 1 & 5 \\
\hline
\end{tabular}




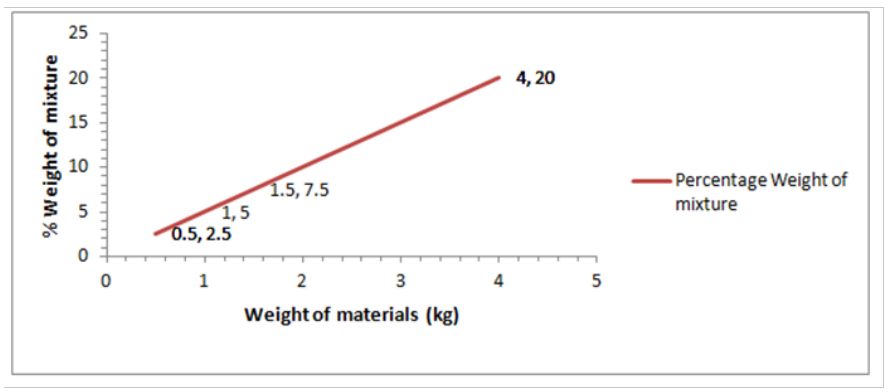

Figure 5 Percent weight of mixture against weight of the materials $(\mathrm{kg})$.

From Table 2, the different test carried out included $20 \mathrm{~kg}, 60 \mathrm{~kg}$, $80 \mathrm{~kg}$ and $100 \mathrm{~kg}$ of feed at different intervals of 5,10,15,20,25 and 30 minutes to determine the efficiency and mixing rate of the machine. Results obtained show that the machine fully mixed the materials at 15 to 20 minutes. When the weight was increased to $60 \mathrm{~kg}$, the materials were fully mixed at 20 minutes and at $100 \mathrm{~kg}$ the thorough mixing was achieved at 30 minutes. This shows that the mixing capabilities of the machine is effective and efficient.

Table 2 Mixing time and mixing rate of different weight of feed

\begin{tabular}{llll}
\hline S/N & $\begin{array}{l}\text { Mixture weight } \\
(\mathbf{k g})\end{array}$ & $\begin{array}{l}\text { Mixing time } \\
(\text { minutes) }\end{array}$ & Mixing rate \\
\hline 1 & 20 & 5 & Slightly mixed \\
2 & 60 & 10 & Fully mixed \\
3 & 80 & 18 & Fully mixed \\
4 & 100 & 20 & Fully mixed
\end{tabular}

Figure 6 shows the graph of weight of mixture with its corresponding mixing time. Increase in weight of mixture increases the mixing time and vice versa.

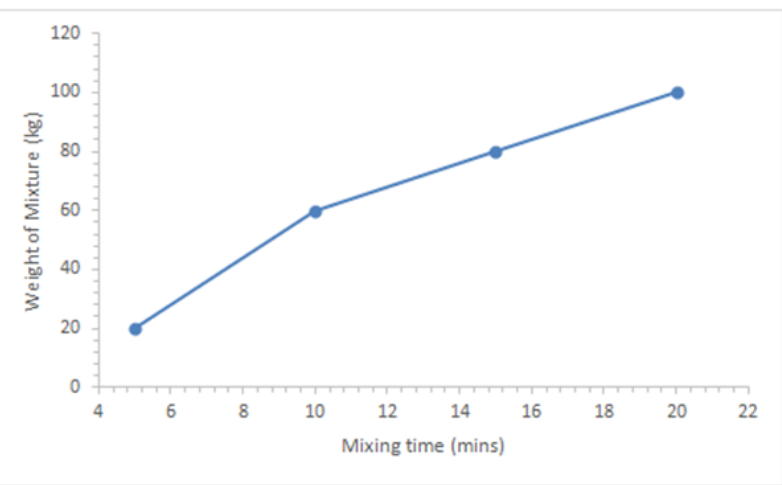

Figure 6 Weight of mixture and mixing time.

\section{Conclusion}

The horizontal livestock feed mixer was designed, fabricated and the performance evaluation was successfully carried out on the mixer. It is relatively cheaper than the machines available at present used for the same purpose in the market and its performance evaluation shows that it is an efficient machine. The higher the weight of mixture, the higher the mixing time and vice versa.

\section{Recommendations}

Further research should be carried out to allow the machine accommodate more volume of feeds. It is recommended that the developed machine be subjected to testing throughout the year for more performance evaluation. The machine should be fixed on an anti-vibration mounting in other to reduce the vibrations created during operation. The use of a conveyor system may be considered for use as this will ease delivery of materials into the mixer.

\section{Acknowledgements}

None.

\section{Conflict of interest}

The author declares no conflict of interest.

\section{References}

1. Balami AA, Adgidzi D, Mu'azu A. Development and Testing of an Animal Feed Mixing Machine. International Journal of Basic and Applied Sciences. 2013;1(3):491-502.

2. Kwari ID, Igwebuike JU. Performance of broiler chickens fed with graded levels of African locust bean (Parkia biglobosa) pulp. Proc. 6th Annual Animal Science Association of Nigeria, 2001. p. 67.

3. Diarra SS, Kwari ID, Kwari HD. Effect of substituting wheat bran with millet bran on nutrients digestibility and intestinal morphology of broiler chickens. Proc. 6th Annual Animal Science Association of Nigeria. 2001. p. 64 .

4. Reddy DV. Principles of Animal Nutrition and Feed Technology. 2nd ed. SI: Oxford and IBH Publishing Company Pvt Limited; 2001.

5. Wilson G Pond, David B. Church. Basic Animal Nutrition and Feeding. 5th ed. SI: Wiley Publication; 2007.

6. Adgidzi D, Mu'azu A, Olorunsogo ST. Design considerations of mixerpelleting machine for processing animal feeds. 7th annual engineering conference, School of Engineering and Engineering Technology, FUT Minna; 2006.

7. Chikwado UK. Development and Performance Test of Poultry Feed Mixing and Pelleting Machine. Int Journal of Science and Research. 2015;4(6):1161-1166.

8. New MB. Feed and feeding of fish and shrimp. Rome: ADCP/REP/87/26, FAO/UNDP; 2007.

9. Dogo HA. The effects of Different Levels of Palm kernel cake on performance and Carcass Characteristics of Broiler Chickens. 2001:49.

10. Khurmi RS, Gupta JK. A Textbook of Machine Design. New Delhi: Eurasia Publishing House; 2005.

11. Shafiur R, Drisco RH. Density of Fresh and Frozen Seafood. Journal of Food Processing Engineering. 1994;17(2):121-140.

12. Shigley JE. Mechanical Engineering Design. 6th ed. New York: McGrawHill; 2001

13. Cary HB, Helzer SC. Modern Welding Technology. New Jersey: Person Education; 2005. 